\title{
LEVANTAMENTO DO DESEMPENHO EM MATEMÁTICA FINANCEIRA DE ESTUDANTES CONCLUINTES DO ENSINO MÉDIO NA CIDADE DE GUANHÃES ${ }^{1}$
}

\author{
Wálmisson Régis de Almeida ${ }^{2}$ \\ José Fernandes da Silva \\ Graziele Chaves Pereira \\ Higor Nilton Braga de Matos
}

\begin{abstract}
RESUMO
O presente artigo tem como objetivo analisar os dados de uma pesquisa relacionados ao desempenho em Matemática Financeira de estudantes concluintes do Ensino Médio na cidade de Guanhães/MG. A pesquisa é mista, ou seja, apresenta abordagens qualitativas, porém elementos quantitativos subsidiam a discussão. $\mathrm{O}$ instrumento de coleta de dados consistiu em levantamento bibliográfico e aplicação de questionário a 245 estudantes do $3^{\circ}$ Ano do Ensino Médio. Os resultados mostram que, embora os currículos preconizem o mínimo de conhecimento com relação aos conteúdos de Matemática Financeira e que os participantes considerem a temática importante para sua vida cotidiana, o índice de acertos de itens básicos se mostra abaixo do esperado. Tal fato demanda uma reflexão por parte dos educadores sobre o papel de aliar as vivências sociais, especialmente aquelas relacionadas ao mundo financeiro, ao currículo proposto.
\end{abstract}

Palavras-chave: Educação financeira. Ensino e aprendizagem de matemática. Currículo de matemática.

\section{SURVEY OF PERFORMANCE IN FINANCIAL MATHEMATICS OF HIGH SCHOOL CONCLUDING STUDENTS IN GUANHÃES CITY}

\begin{abstract}
This article aims to analyze the data of a research related to the performance in Financial Mathematics of high school students in the city of Guanhães/MG. The research is mixed, thatis, it presents qualitative approaches, but quantitative elements support the discussion. The data collection instrument consisted of a bibliographic survey and the application of a question naire to 245 students of the 3rd year of high school. The results show that, although the curricula advocate a minimum of knowledge in relation to the contents of Financial Mathematics and that the participants consider the theme important for their daily life, the index of correct answers for basic items is lower than expected. This fact demands a reflection on the part of

\section{${ }^{1}$ Como citar este artigo:}

ALMEIDA, W. R. de et al. Levantamento do desempenho em matemática financeira de estudantes concluintes do ensino médio da cidade de Guanhães. ForScience, Formiga, v. 8, n. 2, e00864, jul./dez. 2020. DOI: 10.29069/forscience.2020v8n2.e864.

${ }^{2}$ Autor para correspondência: Wálmisson Régis de Almeida, e-mail: walmisson.almeida@ifmg.edu.br
\end{abstract}


ALMEIDA, W. R. de et al. Levantamento do desempenho em matemática financeira de estudantes concluintes do ensino médio da cidade de Guanhães

educators on the role of combining social experiences, especially those related to the financial world, with the proposed curriculum.

Keywords: Financial education. Mathematics teachingand learning. Mathematics curriculum.

\section{INTRODUÇÃO}

É evidente a importância da Educação Financeira nos tempos atuais para a formação de um cidadão crítico e ativo. Vivemos em uma sociedade de consumo e, em decorrência disto, é necessária a discussão, reflexão e compreensão dos conceitos relacionados às práticas financeiras, o que justifica o fato de este ser um dos tópicos abordados na Matemática da Educação Básica.

Bauman (2008) caracteriza o consumo como uma atividade humana que existiu desde os tempos mais remotos:

O consumo é uma condição, e um aspecto, permanente e irremovível, sem limites temporais ou históricos; um elemento inseparável da sobrevivência biológica que nós humanos compartilhamos com todos os outros organismos vivos. Visto dessa maneira, o fenômeno do consumo tem raízes tão antigas quanto os seres vivos - e com toda certeza é parte permanente e integral de todas as formas de vida conhecidas a partir de narrativas históricas e relatos etnográficos (BAUMAN, 2008, p. 38).

Já o consumismo, segundo Dantas (2007), é uma compulsão caracterizada pela busca incessante de objetos novos, mesmo que não haja necessidade dos mesmos. Ainda, de acordo com o citado autor, após a industrialização, criou-se uma mentalidade de que quanto mais se consome, mais se tem garantias de bem-estar, de prestígio e de valorização.

No que tange a aspectos relacionados ao ensino, Borges (1999) apresenta uma relação entre a educação e as formas de consumo, na qual se destaca a função social da escola como instituição formadora dos indivíduos, afirmando que:

A educação para o consumo como matéria escolar já existe em vários países há alguns anos e tem sido vista pela Organização das Nações Unidas como a oportunidade de criar, inovar e mudar um país, pois a escola é a instituição mais capacitada para formar indivíduos autônomos, capazes de acompanhar as mudanças do mundo (BORGES, 1999, p. 27).

Rosetti Junior e Shimiguel (2009) corroboram com o supracitado quando defendem que a Educação Financeira pode contrapor o paradigma consumista instaurado no presente século, 
ALMEIDA, W. R. de et al. Levantamento do desempenho em matemática financeira de estudantes concluintes do ensino médio da cidade de Guanhães

propondo que a escola, por meio de seus currículos, busque o desenvolvimento de competências e habilidades que propiciem uma postura autônoma do estudante.

Justificando as discussões nessa temática, Saito (2007) aponta que a abordagem de temas relacionados às práticas financeiras se dê a partir das transformações econômicas ocorridas em nosso país e para o próprio desenvolvimento deste. Em momentos nos quais se experimenta aumento da oferta de crédito, observa-se o crescimento no endividamento da população brasileira que, a partir de bens comprados com grandes prazos de financiamentos, muitas das vezes com juros abusivos, compromete a maior parte da sua renda mensal.

Neste sentido, é importante iniciar as discussões sobre Educação Financeira desde o início da Educação Básica visando auxiliar o estudante para que ele consiga relacionar os conhecimentos escolares ao seu convívio social. Tal perspectiva vai ao encontro de Reis (2013, p. 27) quando afirma que a abordagem de temática do campo financeiro corresponde a: “interpretar, reconhecer, avaliar, utilizar e propor conceitos; onde o estudante consiga relacionar e identificar seu papel em situações cotidianas".

No nosso dia a dia somos requeridos, a todo tempo, a tomar decisões sobre financiamentos de imóveis, veículos, aplicações, investimentos financeiros, compras com cartões de crédito, efetivação de empréstimos, dentre outras. Tal fato exige que, enquanto cidadãos, tenhamos conhecimentos e capacidade de análise crítica sobre as transações financeiras.

Face ao exposto, o objetivo desta pesquisa foi analisar o desempenho de estudantes do $3^{\text {o }}$ Ano do Ensino do Médio quando confrontados com situações-problema que envolvam conhecimentos de Matemática Financeira, bem como a importância dada por estes a ao estudo desse tema.

\section{REFERENCIAL TEÓRICO}

\subsection{A Educação Financeira para os Anos Finais da Educação Básica}

A Matemática é de fundamental importância na formação acadêmica e sociocultural das pessoas e, dentro dos conteúdos trabalhados na Educação Básica, as temáticas que remetem ao mundo financeiro têm se tornado protagonistas no desenvolvimento do processo acadêmico, pois possuem papel fundamental na formação de cidadãos críticos e conscientes de suas decisões. Apesar disso, percebe-se que uma parcela considerável da nossa sociedade passa pela 
ALMEIDA, W. R. de et al. Levantamento do desempenho em matemática financeira de estudantes concluintes do ensino médio da cidade de Guanhães

escola, estuda matemática e, mesmo assim, demonstra dificuldades com noções elementares de finanças. Como possibilidade para romper com essa situação, Silva e Powell (2013, p.12-13), realizaram a seguinte discussão:

\begin{abstract}
A Educação Financeira Escolar constitui-se de um conjunto de informações por meio do qual os estudantes são introduzidos no universo do dinheiro e estimulados a produzir uma compreensão sobre finanças e economia, por meio de um processo de ensino, que os torne aptos a analisar, fazer julgamentos fundamentados, tomar decisões e ter posições críticas sobre questões financeiras que envolvam sua vida pessoal, familiar e da sociedade em que vivem.
\end{abstract}

Nesta perspectiva, a formação dos estudantes em Matemática Financeira deveria ser pensada e construída visando desde as séries iniciais até o final da Educação Básica (SILVA; POWELL, 2013), pois crianças e jovens sofrem com massivas informações da televisão, internet e redes sociais, as quais incentivam o consumo.

É importante iniciar as discussões de Educação Financeira desde os primeiros anos de escolaridade, pois ao chegar Ensino Médio, que é uma fase que antecede o início da carreira profissional e/ou trabalho, o estudante necessita consolidar seus conhecimentos conforme aponta a Base Nacional Comum Curricular (BNCC):

[...] no Ensino Médio o foco é a construção de uma visão integrada da Matemática, aplicada à realidade, conforme anteriormente anunciado. Nesse contexto, quando a realidade é a referência, é preciso levar em conta as vivências cotidianas dos estudantes do Ensino Médio, envolvidos, em diferentes graus dados por suas condições socioeconômicas, pelos avanços tecnológicos, pelas exigências do mercado de trabalho, pela potencialidade das mídias sociais, entre outros (BRASIL, 2018, p. 518).

Contudo, Rosetti Junior e Schimiguel (2009) já refletiam que a metodologia utilizada tradicionalmente nas salas de aula pode ser entrave à efetivação das inovações curriculares. Tal fato impõe a necessidade de repensar as práticas pedagógicas de Matemática, de forma que a abordagem dos conteúdos suscite possibilidades de questionamentos do mundo real, visto que “... um dos desafios para a aprendizagem da Matemática no Ensino Médio é exatamente proporcionar aos estudantes a visão de que ela não é um conjunto de regras e técnicas, mas faz parte de nossa cultura e de nossa história” (BRASIL, 2018, p. 522).

Neste sentido, para consolidar as aprendizagens de Matemática, em especial, as discussões em Educação Financeira, é necessário que as práticas de ensino desta ciência busquem dar protagonismo aos estudantes. Se o principal papel da escola é formar cidadãos conscientes e críticos, o professor de Matemática deve estar atento ao cotidiano do discente, pois deste lugar pode emergir práticas financeiras valiosas para a sala de aula. Assim, nosso 
ALMEIDA, W. R. de et al. Levantamento do desempenho em matemática financeira de estudantes concluintes do 5 ensino médio da cidade de Guanhães

olhar de educadores podem nos remeter agora a um pensar sobre nós mesmos, sobre quem educa sobre quem aprende e sobre a escola (MATURANA,1999 apud LIMA; SAUER, 2005). Segundo os citados autores é a educação, em todos os níveis, que fomenta e impulsiona a formação humana e que pode propiciar as melhores oportunidades de desenvolvimento das nossas crianças e jovens e também, por que não, dos adultos.

\subsection{A Matemática Financeira na Educação Básica sob a Ótica Curricular}

Nas escolas em geral, os conteúdos da Matemática Financeira são apresentados por meio de técnicas de memorização de fórmulas e situações que, em sua grande maioria, não retratam a realidade na qual o estudante está inserido. Tal fato, para D’Ambrósio (2002) pode ser reconstruído, pois:

O ciclo de aquisição do conhecimento da matemática pode ser mais eficiente se emergir de fenômenos que têm origem na realidade. Ao se referir a Matemática nas escolas, ele diz que o maior desafio dos matemáticos e educadores matemáticos é fazer uma matemática integrada no pensamento e no mundo moderno (D’AMBROSIO, 2002, p. 30).

A abordagem dos conteúdos matemáticos na Educação Básica necessita propiciar aos estudantes a capacidade de resolver problemas, de forma a aplicar os conhecimentos construídos à realidade por eles vivenciada. Segundo a Lei de Diretrizes e Bases da Educação (LDB), o ensino de qualidade "tem por finalidades desenvolver o educando, assegurar-lhe a formação comum indispensável para o exercício da cidadania e fornecer-lhe meios para progredir no trabalho e em estudos posteriores (BRASIL, 1996, p. 17).

No fim da década de 90, concernente às orientações curriculares, os Parâmetros Curriculares Nacionais para o Ensino Médio (PCN) (2002) já apontavam as competências a serem desenvolvidas no ensino da Matemática:

\footnotetext{
Representação e comunicação, que envolvem a leitura, a interpretação e a produção de textos nas diversas linguagens e formas textuais características dessa área do conhecimento; - investigação e compreensão, competência marcada pela capacidade de enfrentamento e resolução de situações-problema, utilização dos conceitos e procedimentos peculiares do fazer e pensar das ciências; - contextualização das ciências no âmbito sociocultural, na forma de análise crítica das ideias e dos recursos da área e das questões do mundo que podem ser respondidas ou transformadas por meio do pensar e do conhecimento científico (BRASIL, 2002, p. 113).
}

Diante do exposto, é mister afirmar que o ensino da Matemática e, em especial as temáticas que abordem aspectos da vida financeira, deve se pautar na criação de estratégias que 
ALMEIDA, W. R. de et al. Levantamento do desempenho em matemática financeira de estudantes concluintes do ensino médio da cidade de Guanhães

possibilitem aos estudantes refletir sobre suas práticas sociais que envolvem o uso do dinheiro e, não apenas calcular e resolver exercícios sem fundamentação.

\begin{abstract}
A Matemática no Ensino Médio tem um valor formativo, que ajuda a estruturar o pensamento e o raciocínio dedutivo, porém também desempenha um papel instrumental, pois é uma ferramenta que serve para a vida cotidiana e para muitas tarefas específicas em quase todas as atividades humanas. Em seu papel formativo, a Matemática contribui para o desenvolvimento de processos de pensamento e a aquisição de atitudes, cuja utilidade e alcance transcendem o âmbito da própria Matemática [...] (BRASIL, 1999, p. 40).
\end{abstract}

Como reflexo das discussões oriundas dos PCN, as diretrizes curriculares do Estado de Minas Gerais, o Conteúdo Básico Comum (CBC) para o ensino de Matemática, que vigoraram até 2019, apresentavam, conforme Quadro 1, as habilidades que um estudante deveria desenvolver ao estudar a Matemática Financeira:

\begin{tabular}{|c|c|c|c|}
\hline \multicolumn{2}{|r|}{ Eixo Temático/Ano } & Tópicos & Habilidades \\
\hline 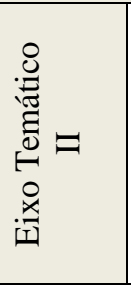 & $\begin{array}{l}\text { CBC para o 10 Ano } \\
\text { Funções Elementares e } \\
\text { Modelagem } \\
\text { Tema 6: Matemática } \\
\text { Financeira }\end{array}$ & $\begin{array}{l}13 . \\
\text { Matemática } \\
\text { Financeira }\end{array}$ & $\begin{array}{l}\text { 13.1. Resolver problemas que envolvam o conceito de } \\
\text { porcentagem. } \\
\text { 13.2. Resolver problemas que envolvam o conceito de } \\
\text { juros simples ou compostos. } \\
\text { 13.3. Resolver situações-problema que envolvam o } \\
\text { cálculo de prestações em financiamentos com um número } \\
\text { pequeno de parcelas. }\end{array}$ \\
\hline 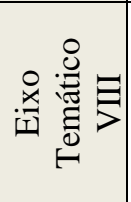 & $\begin{array}{l}\text { CBC para o 30 Ano } \\
\text { - Funções Elementares e } \\
\text { Modelagem } \\
\text { Tema 20: Matemática } \\
\text { Financeira }\end{array}$ & $\begin{array}{l}44 . \\
\text { Matemática } \\
\text { Financeira }\end{array}$ & $\begin{array}{l}\text { 44.1. Comparar rendimentos em diversos tipos de } \\
\text { aplicações financeiras. } \\
\text { 44.2. Comparar e emitir juízo sobre diversas opções de } \\
\text { financiamento. }\end{array}$ \\
\hline
\end{tabular}

Quadro 1 - Conteúdo Básico Comum de Matemática do Ensino Médio - Tema: Matemática Financeira Fonte: Secretaria de Estado de Educação de Minas Gerais (2007).

Destaca-se que no âmbito da $2^{\mathrm{a}}$ série do Ensino Médio o referido documento tampouco aborda aspectos da temática "financeira".

Em relação à última mudança curricular nacional, percebe-se que a alteração nas metodologias de ensino é reforçada no âmbito da Base Nacional Comum Curricular (BNCC) quando aponta a necessidade de uma formação que possibilite ao estudante "inserir-se de forma ativa, crítica, criativa e responsável em um mundo do trabalho cada vez mais complexo e imprevisível" (BRASIL, 2018, p. 465). Nesse sentido, o domínio das habilidades básicas sob aspectos financeiros é fundamental para uma formação consolidada.

O próprio documento apresenta na descrição das competências 3 e 5, intituladas respectivamente "Utilizar estratégias, conceitos e procedimentos matemáticos, em seus campos - Aritmética, Álgebra, Grandezas e Medidas, Geometria, Probabilidade e Estatística -para 
ALMEIDA, W. R. de et al. Levantamento do desempenho em matemática financeira de estudantes concluintes do ensino médio da cidade de Guanhães

interpretar, construir modelos e resolver problemas em diversos contextos, analisando a plausibilidade dos resultados e a adequação das soluções propostas, de modo a construir argumentação consistente" e "Investigar e estabelecer conjecturas a respeito de diferentes conceitos e propriedades matemáticas, empregando recursos e estratégias como observação de padrões, experimentações e tecnologias digitais, identificando a necessidade, ou não, de uma demonstração cada vez mais formal na validação das referidas conjecturas", habilidades específicas que envolvem o conhecimento desse conteúdo. Entre elas, pode-se destacar:

(EM13MAT303) Resolver e elaborar problemas envolvendo porcentagens em diversos contextos e sobre juros compostos, destacando o crescimento exponencial. (EM13MAT304) Resolver e elaborar problemas com funções exponenciais nos quais é necessário compreender e interpretar a variação das grandezas envolvidas, em contextos como o da Matemática Financeira e o do crescimento de seres vivos microscópicos, entre outros.

(EM13MAT305) Resolver e elaborar problemas com funções logarítmicas nos quais é necessário compreender e interpretar a variação das grandezas envolvidas, em contextos como os de abalos sísmicos, pH, radioatividade, Matemática Financeira, entre outros.

(EM13MAT503) Investigar pontos de máximo ou de mínimo de funções quadráticas em contextos da Matemática Financeira ou da Cinemática, entre outros (BRASIL, 2018, p. 528-533).

A título de sintetizar as informações supracitadas, vale ressaltar, conforme aponta Coutinho e Teixeira (2015), a importância de desenvolver estratégias respaldadas em fundamentos teóricos que possam estabelecer um diálogo entre as práticas pedagógicas e a Educação Financeira. Ainda conforme os autores citados é um desafio constante para os pesquisadores, educadores e gestores da educação proporcionar debates que incluam os jovens estudantes.

\section{MATERIAL E MÉTODOS}

A pesquisa em questão é de natureza mista, ou seja, combina aspectos das pesquisas quantitativas com os métodos das qualitativas, conforme aponta Dal-Farra e Lopes (2013). Para a realização da pesquisa, foi considerada como população os estudantes do $3^{\circ}$ Ano do Ensino Médio das Escolas da Rede Estadual do município de Guanhães/MG, totalizando nove turmas, distribuídas em duas escolas. Desse universo, participaram efetivamente da pesquisa 245 estudantes.

Guanhães é um município do estado de Minas Gerais, situado na região Leste do estado, conhecido como Vale do Rio Doce. Sua população segundo o Instituto Brasileiro de Geografia 
ALMEIDA, W. R. de et al. Levantamento do desempenho em matemática financeira de estudantes concluintes do 8 ensino médio da cidade de Guanhães

e Estatística (IBGE) (2017) estimada em 2018 é de 34.057 (trinta e quatro mil, cinquenta e sete) habitantes. O município, segundo dados do IBGE- $2017^{3}$, ocupa uma área territorial de aproximadamente 1.075 (um mil e setenta e cinco) $\mathrm{km}^{2}$. Nos dias de hoje, pode ser considerada uma cidade em expansão, tanto em tamanho populacional quanto em desenvolvimento. Tais características, que a consolida como polo regional, foram fundamentais para a sua escolha como campo de pesquisa.

A cidade atende a mais de 30 (trinta) municípios da região por meio de prestação de serviços, principalmente nos setores de hotelaria, comércio, trabalho, saúde, educação, bancário e logístico. O município pertence aos circuitos turísticos da Estrada Real ${ }^{4}$ e das Trilhas do Rio Doce ${ }^{5}$.

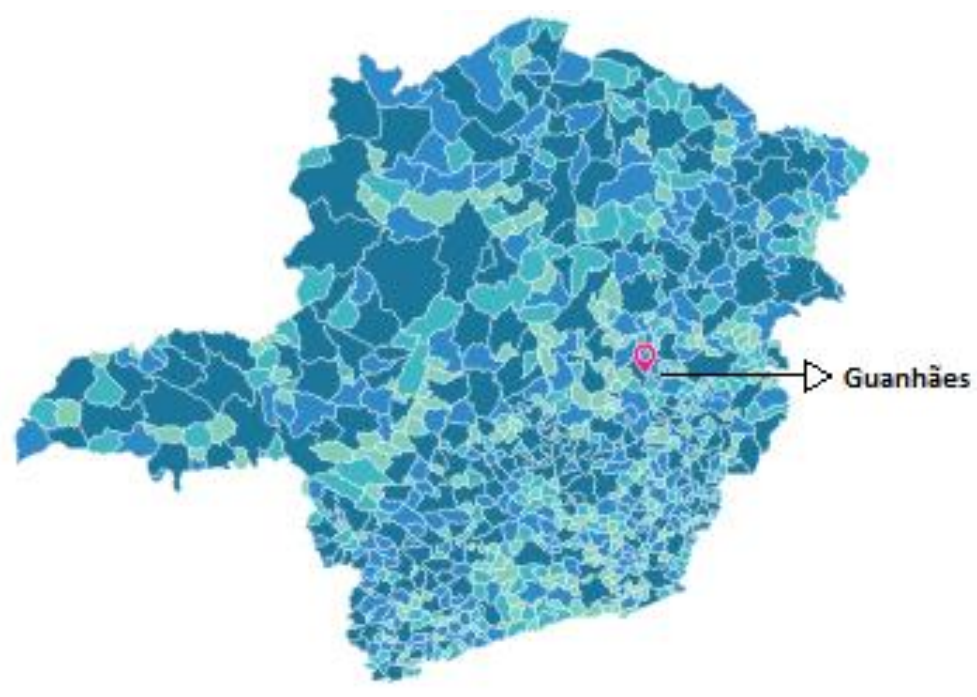

Legenda

$\begin{array}{llll}\text { até } 4.709 & \text { até } 8.005 & \text { até } 17.243 & \text { mais que } \\ \text { pessoas } & \text { pessoas } & \text { pessoas } & 17.243 \\ & & & \text { pessoas }\end{array}$

Figura 1 - Localização do Município de Guanhães/MG

$\mathrm{Na}$ fase de investigação, os instrumentos utilizados para a coleta de dados foram pesquisas bibliográficas (LAKATOS; MARCONI, 2003) e confecção de um questionário (GIL, 2002) que contou com 10 (dez) questões objetivas sendo 2 (duas) delas relacionadas à importância da aprendizagem de temáticas de práticas financeiras, nas quais os estudantes foram questionados sobre a importância dada aos conhecimentos deste tema para sua vida cotidiana; e as demais relacionadas à resolução de situações-problema. O questionário foi

\footnotetext{
${ }^{3}$ Disponível em: https://cidades.ibge.gov.br/brasil/mg/guanhaes. Acesso em: 13 nov. 2019.

${ }^{4}$ Disponível em: http://www.institutoestradareal.com.br/estradareal. Acesso em: 07 ago. 2019.

${ }^{5}$ Disponível em: http://www.trilhasdoriodoce.com.br/. Acesso em: 07 ago. 2019.
} 
ALMEIDA, W. R. de et al. Levantamento do desempenho em matemática financeira de estudantes concluintes do 9 ensino médio da cidade de Guanhães

aplicado pelos pesquisadores no horário das aulas regulares de Matemática com autorização e supervisão dos professores regentes.

Os itens do questionário relacionados à resolução de situações-problema de Matemática Financeira foram retirados de avaliações externas direcionadas à Educação Básica, tendo como prioridade abordagem de cálculo de porcentagens, investimentos, análise de financiamentos e empréstimos. Tais itens foram considerados significativos e em consonância com as proposições do currículo de Matemática direcionado ao público-alvo.

Por se tratar de um primeiro levantamento no âmbito de uma pesquisa mais abrangente, os dados apresentados neste artigo são originados da fase denominada diagnóstica, na qual se analisou o desempenho dos participantes, sem levar em consideração as estratégias construídas ao longo da resolução.

Em relação às escolhas teóricas, buscaram-se as reflexões no âmbito da Educação Financeira, pois o estudo é diretamente relacionado a esta temática. A abordagem curricular, tanto a nível da Rede de Ensino do Estado de Minas Gerais, quanto a nível nacional, foi importante para situar o conteúdo de Matemática Financeira ao longo da Educação Básica.

\section{RESULTADOS E DISCUSSÃO}

A seguir, apresenta-se uma discussão de cada item do questionário, destacando os requisitos necessários para a sua resolução. Justifica-se a discussão desses itens pelo fato de que eles foram objeto de estudo e das reflexões no âmbito do trabalho. Em seguida discute-se o desempenho dos participantes, bem como os aspectos relacionados à importância que estes dão à Matemática/Educação Financeira.

\subsection{Sobre Cálculos de Porcentagem}

Nessa categoria, são apresentadas duas situações nas quais são exigidos conhecimentos sobre a operação de porcentagem. O cálculo de porcentagens é indispensável nas operações de práticas financeiras, podendo ser considerado um pré-requisito para o estudo de investimentos e empréstimos (LOPES, 2013). Trata-se, portanto, de um conhecimento instrumental e básico para que o cidadão possa tomar decisões no que concerne à posição de consumidor. 
(Enem) A baixa procura por carne bovina e o aumento de oferta de animais para abate fizeram com que o preço da arroba do boi apresentasse queda para o consumidor. No ano de 2012, o preço da arroba do boi caiu de $R \$ 100,00$ para $R \$ 93,00$.

Disponível em: www.diariodemarilia.com.br. Acesso em: 14 ago. 2012

Com o mesmo valor destinado à aquisição de carne, termos de perda ou ganho, o consumidor a) ganhou $6,5 \%$ em poder aquisitivo de carne.b) ganhou $7 \%$ em poder aquisitivo de carne.

c) ganhou 7,5\% em poder aquisitivo de carne.d) perdeu $7 \%$ em poder aquisitivo de carne.

e) perdeu 7,5\% em poder aquisitivo de carne.

Quadro 2 - Item envolvendo o conteúdo de porcentagem na prova do ENEM/2017

Fonte: INEP (2017).

Nesse item, objetivou-se que os participantes determinassem o quanto eles comprariam de carne com os mesmos 100 reais, ou seja, $\frac{100}{93} \cong 1,075$. Desta forma, poderiam chegar à conclusão que haveria um ganho de 7,5\% em poder aquisitivo. Tal fato remete às discussões de Silva e Powell (2013), quando afirmam que a educação financeira escolar deve promover a condição de cidadania e consciência crítica para tomadas de decisões.

No item do Quadro 3 buscou-se evidenciar o conhecimento dos participantes sobre preços de produção e venda de um determinado produto, levando em consideração a variação percentual do valor de custo.

(Encceja):Para a produção de um produto de massa 1,5 kg, uma indústria utiliza 0,5 kg da matéria-prima A e 1,0 kg da matéria-prima B. O preço de custo, por quilo, é de $R \$ 15,00$ para a matéria-prima $A$ e de $R \$ 4,50$ para a matéria-prima B. O valor de venda desse produto é calculado acrescentando-se $50 \%$ ao valor de custo total dessas duas matérias-primas.

A partir do próximo mês, o preço de custo por quilograma da matéria-prima A sofrerá um aumento de $R \$$ 6,00. Entretanto, deseja-se manter a mesma composição na produção e o mesmo valor de venda do produto. Para isso, a indústria analisa que necessitará reduzir o percentual de acréscimo aplicado sobre o valor de custo para calcular o seu valor de venda.

Para atender a essas condições, o novo percentual aplicado sobre o valor de custo deve ser de:
a) $12,8 \%$
b) $14,7 \%$
c) $20,0 \%$
d) $25,0 \%$

Quadro 3 - Item envolvendo o conteúdo de porcentagem na prova do ENCCEJA/2017

Fonte: INEP (2017).

Nesse caso, para a resolução, era esperado que os discentes operassem igualando os custos de venda antes e depois do reajuste, ou seja, $1,5 \cdot(0,5 \cdot 15+1 \cdot 4,5)=x(0,5 \cdot 21+1$. $4,5) \Rightarrow 18=15 x \Rightarrow x=1,2$. Assim, eles poderiam encontrar o novo percentual que é de $20 \%$. Observa-se que o problema aborda uma situação do mundo do trabalho que possibilita um diálogo entre a Matemática escolar e a Matemática prática. Esse enlace está em consonância com os pressupostos da BNCC (BRASIL, 2018) que destaca a necessidade de integração da Matemática à realidade. 
ALMEIDA, W. R. de et al. Levantamento do desempenho em matemática financeira de estudantes concluintes do ensino médio da cidade de Guanhães

\subsection{Sobre Investimentos}

Para esse tópico, foram selecionados dois itens envolvendo situações-problema para as quais são exigidos conhecimentos sobre investimentos.

(Enem)Um jovem investidor precisa escolher qual investimento lhe trará maior retorno financeiro em uma aplicação de $R \$ 500,00$. Para isso, pesquisa o rendimento e o imposto a ser pago em dois investimentos: poupança e CDB (Certificado de Depósito Bancário). As informações obtidas estão resumidas no quadro:

\begin{tabular}{|l|c|c|}
\hline & $\begin{array}{c}\text { Rendimento } \\
\text { mensal (\%) }\end{array}$ & $\begin{array}{c}\text { IR (imposto de } \\
\text { renda) }\end{array}$ \\
\hline POUPANÇA & 0,560 & ISENTO \\
\hline CDB & 0,876 & $4 \%$ (sobre o ganho) \\
\hline
\end{tabular}

Para o jovem investidor, ao final de um mês, a aplicação mais vantajosa é

a) a poupança, pois totalizará um montante de $R \$ 500,56 . b)$ o $C D B$, pois totalizará um montante de $R \$ 504,38$.

c) o $C D B$, pois totalizará um montante de $R \$ 504,21 . d)$ o $C D B$, pois totalizará um montante de $R \$ 500,87$.

Quadro 4 - Item envolvendo o conteúdo de investimentos na prova do ENEM/2011

Fonte: INEP (2011).

Era esperado que os participantes, ao resolvê-lo, calculassem o montante das duas aplicações e efetuassem a comparação entre as mesmas. No caso da poupança, são 500 · $1,0056=502,80$ reais. Para o $\mathrm{CDB}$, tem-se $500 \cdot 1,00876-500 \cdot 0,00876 \cdot 0,04 \cong$ 504,21. Desta forma, poderiam visualizar que a melhor aplicação para o investidor é o CDB. Isso se configura na tomada de decisões pelo cidadão (SILVA; POWELL, 2013).

No Quadro 5, apresenta-se uma situação que envolve o valor de impostos a ser pago pelo contribuinte à Receita Federal em caso de venda de ações da Bolsa de Valores.

(Enem) $O$ contribuinte que vende mais de $R \$ 20$ mil de ações em Bolsa de Valores em um mês deverá pagar Imposto de Renda. O pagamento para a Receita Federal consistirá em $15 \%$ do lucro obtido com a venda das ações.

Disponivel em: www1.folha.uol.com.br. Acesso em: 26 abr. 2010 (adaptado).

Um contribuinte que vende por $R \$ 34$ mil um lote de ações que custou $R \$ 26$ mil terá de pagar de Imposto de Renda à Receita Federal o valor de:

$\begin{array}{lllll}\text { a) } R \$ 900,00 & \text { b) } R \$ 1.200,00 & \text { c) } R \$ 2.100,00 & \text { d) } R \$ 3.900,00 & \text { e) } R \$ 5.100,00\end{array}$

Quadro 5 - Item envolvendo o conteúdo de investimentos na prova do ENEM/2013

Fonte: INEP (2013).

Como pode ser observado, o item afirma que uma pessoa obteve um lote de ações por um valor de $\mathrm{R} \$ 26$ mil reais e, depois o vendeu pelo valor de $\mathrm{R} \$ 34$ mil reais. O lucro adquirido por essa pessoa pode ser encontrado a partir da subtração entre o valor comprado e o valor vendido do lote de ações. Bastava, portanto, que os estudantes realizassem a seguinte operação: Lucro $=34.000-26.000 \Rightarrow$ Lucro $=8.000$. Diante desse resultado, era necessário que encontrassem a porcentagem de $15 \%$ sobre esse valor. Portanto, precisavam realizar o seguinte cálculo matemático: $15 \%$ de $8 \cdot 000=0,15 \times 8 \cdot 000=1.200$. Assim, conseguiriam chegar ao valor 
ALMEIDA, W. R. de et al. Levantamento do desempenho em matemática financeira de estudantes concluintes do ensino médio da cidade de Guanhães

de impostos que deveria ser pago pela pessoa para a Receita Federal, que seria de $\mathrm{R} \$ 1.200,00$. A habilidade para lidar com situações desta natureza requer ações de alfabetização financeira, a qual exige capacidade crítica da tomada de decisões (POTRICH; VIEIRA, 2018).

\subsection{Sobre Financiamentos e Empréstimos}

Nessa categoria, foram apresentados quatro itens para os quais são exigidos conhecimentos básicos sobre financiamentos e empréstimos, temas estes recorrentes no cotidiano de nossa sociedade capitalista.

(Enem) Um casal realiza um financiamento imobiliário de $R \$ 180.000,00$, a ser pago em 360 prestações mensais, com taxa de juros efetiva de $1 \%$ ao mês. A primeira prestação é paga um mês após a liberação dos recursos e o valor da prestação mensal é de $R \$ 500,00$ mais juro de 1\% sobre o saldo devedor (valor devido antes do pagamento). Observe que, a cada pagamento, o saldo devedor se reduz em $R \$ 500,00$ e considere que não há prestação em atraso. Efetuando o pagamento dessa forma, o valor, em reais, a ser pago ao banco na décima prestação é de
a) $R \$ 2.075,00$. b) $R \$ 2.093,00$.
c) $R \$ 2.138,00$.
d) $R \$ 2.255,00$.
e) $R \$ 2.300,00$

Quadro 6 - Item envolvendo o conteúdo de financiamentos e empréstimos na prova do ENEM/2015 Fonte: INEP (2015).

Esse item aborda o Sistema de Amortização Constante (SAC), muito utilizado em financiamentos imobiliários dos bancos públicos e privados brasileiros. Apesar disso, não é necessário conhecimento prévio do tema, já que as informações necessárias se encontram no enunciado do item, principalmente o trecho que diz "Observe que, a cada pagamento, o saldo devedor se reduz em R \$ 500,00”. Na décima prestação, temos 9 etapas de amortização e, assim a dívida será de $180.000-9 \cdot 500=175.500$ reais. A parcela será então de $500+0,01$. $175.500=2.255$ reais. Compreender situações desta natureza é fundamental e está em consonância com as proposições da Estratégia Nacional de Educação Financeira (ENEF), em relatório publicado em 2013, que destaca a importância do controle efetivo dos gastos.

(Encceja) Para comprar um refrigerador, uma pessoa realizou uma pesquisa de preço em quatro lojas diferentes. O pagamento será à vista. Os preços obtidos estão indicados a seguir.

\begin{tabular}{|l|l|l|}
\hline Loja I & $R \$ 1500,00$ & Desconto de $5 \%$ para pagamento à vista. \\
\hline Loja II & $R \$ 1550,00$ & Desconto de $10 \%$ para pagamento à vista. \\
\hline Loja III & $R \$ 1600,00$ & Desconto de $12 \%$ para pagamento à vista. \\
\hline Loja IV & $R \$ 1650,00$ & Desconto de $8 \%$ para pagamento à vista. \\
\hline
\end{tabular}

Em qual dessas lojas o refrigerador tem o menor preço à vista?
a) $I$
b) II
c) III
d) $I V$

Quadro 7 - Item envolvendo o conteúdo de financiamentos e empréstimos na prova do ENCCEJA/2017 Fonte: INEP (2017). 
Nesse item, o discente precisava calcular o valor à vista do refrigerador nas 4 lojas aplicando o desconto: $(1-0,05) \cdot 1500=R \$ 1.425,00$ na loja $\mathrm{I},(1-0,10) \cdot 1.550=$ $R \$ 1.395,00$ na loja II, $(1-0,12) \cdot 1600=R \$ 1.408,00$ na loja 3 e $(1-0,08) \cdot 1.650=$ $R \$ 1.518,00$ na loja 4. Desta forma, seria encontrada a loja II como a melhor opção.

(Enem): Um empréstimo foi feito à taxa mensal de i\%, usando juros compostos, em oito parcelas fixas e iguais a P. O devedor tem a possibilidade de quitar a dívida antecipadamente a qualquer momento, pagando para isso o valor atual das parcelas ainda a pagar. Após pagar a $5^{a}$ parcela, resolve quitar a dívida no ato de pagar a $6^{a}$ parcela. A expressão que corresponde ao valor total pago pela quitação do empréstimo é:

$$
\begin{aligned}
& \text { a) } P\left[1+\frac{1}{\left(1+\frac{i}{100}\right)}+\frac{1}{\left(1+\frac{i}{100}\right)^{2}}\right] \quad \text { b) } P\left[1+\frac{1}{\left(1+\frac{i}{100}\right)}+\frac{1}{\left(1+\frac{2 i}{100}\right)}\right] \text { c) } P\left[1+\frac{1}{\left(1+\frac{i}{100}\right)^{2}}+\frac{1}{\left(1+\frac{i}{100}\right)^{2}}\right] \text { d) } \\
& P\left[\frac{1}{\left(1+\frac{i}{100}\right)}+\frac{1}{\left(1+\frac{2 i}{100}\right)}+\frac{1}{\left(1+\frac{3 i}{100}\right)}\right] \text { e) } P\left[\frac{1}{\left(1+\frac{i}{100}\right)}+\frac{1}{\left(1+\frac{i}{100}\right)^{2}}+\frac{1}{\left(1+\frac{i}{100}\right)^{3}}\right]
\end{aligned}
$$

Quadro 8 - Item envolvendo o conteúdo de financiamentos e empréstimos na prova do ENEM/2017 Fonte: INEP (2017).

Este item envolve o cálculo do valor presente, dado um valor futuro, uma taxa de juros e um número de períodos. Tal situação apresenta um caso atinente à vida em sociedade em que a compreensão, as habilidades, os comportamentos e as atitudes em relação aos desafios do consumo são essenciais às pessoas (SILVA; POWELL, 2015). Observa-se que para resolvê-lo, o participante precisaria entender que para quitar a dívida, o consumidor deveria pagar a $6^{\mathrm{a}}$ parcela, vencida na data do pagamento e sem desconto e, as parcelas 7 e 8 com seus valores deslocados 1 mês e 2 meses, respectivamente, para a data atual. Para deslocar valores monetários no tempo, basta dividi-los por $\left(1+\frac{i}{100}\right)^{n}$, em que $n$ corresponde ao número de períodos em que se retroage esse valor. Logo, a quantia que quita seu empréstimo é de $P\left[1+\frac{1}{\left(1+\frac{i}{100}\right)}+\frac{1}{\left(1+\frac{i}{100}\right)^{2}}\right]$. Em outras palavras, pode-se afirmar que pra transformar o valor de hoje em valor futuro adiciona-se juros. E no caso de antecipação do valor futuro, para hoje, ganha-se desconto.

Ainda, no contexto financiamentos e empréstimos, o item do Quadro 9 compôs o instrumento de coleta de dados: 
(Encceja) Um banco analisou o perfil de um cliente e ofereceu-lhe um empréstimo de $R \$ 10.000,00$, podendo escolher uma das propostas a seguir:

I - Empréstimo Com Taxa De Juros Simples De 10\% Ao Ano, A Ser Pago Integralmente Após 15 Anos.

II - Empréstimo Com Taxa De Juros Simples De 11\% Ao Ano, A Ser Pago Integralmente Após 16 Anos.

III - Empréstimo Com Taxa De Juros Simples De 20\% Ao Ano, A Ser Pago Integralmente Após 6 Anos.

IV-Empréstimo Com Taxa De Juros Simples De 25\% Ao Ano, A Ser Pago Integralmente Após 5 Anos.

A proposta que gera o menor valor a pagar ao término do empréstimo é:

$\begin{array}{llll}\text { a) } I & \text { b) } I I & \text { c) } I I I & \text { d) } I V\end{array}$

Quadro 9 - Item envolvendo financiamentos e empréstimos oriundo do ENCCEJA/2017

Fonte: INEP (2017).

Esse item aborda o conceito de juros simples, situação na qual a taxa de juros é aplicada sobre o capital. Para resolvê-lo os participantes necessitavam adicionar ao capital do empréstimo os juros devidos, ou seja, $10.000+10.000 \cdot i \cdot n$. Efetuando as contas, encontrariam a proposta III como a que gera o menor valor, $10.000+10.000 \cdot 0,2 \cdot 6=$ $R \$ 22.000,00$.

Os itens discutidos nesta categoria tratam de uma temática presente na vida dos brasileiros que instigados pelo consumismo acabam por realizar buscas constantes por produtos e/ou serviços novos independente da sua necessidade (DANTAS, 2007). Tal comportamento pode ser o gatilho para o processo de endividamento que ocorre, em grande parte, por financiamentos de longo prazo que acabam por comprometer a renda mensal das famílias.

Dando seguimento à análise dos dados da pesquisa, apresenta-se a seguir os resultados da aplicação do questionário. A Figura 1 representa o cenário relacionado à aplicação dos itens supracitados, ou seja, os itens que envolvem conhecimentos de abordagens financeiras:

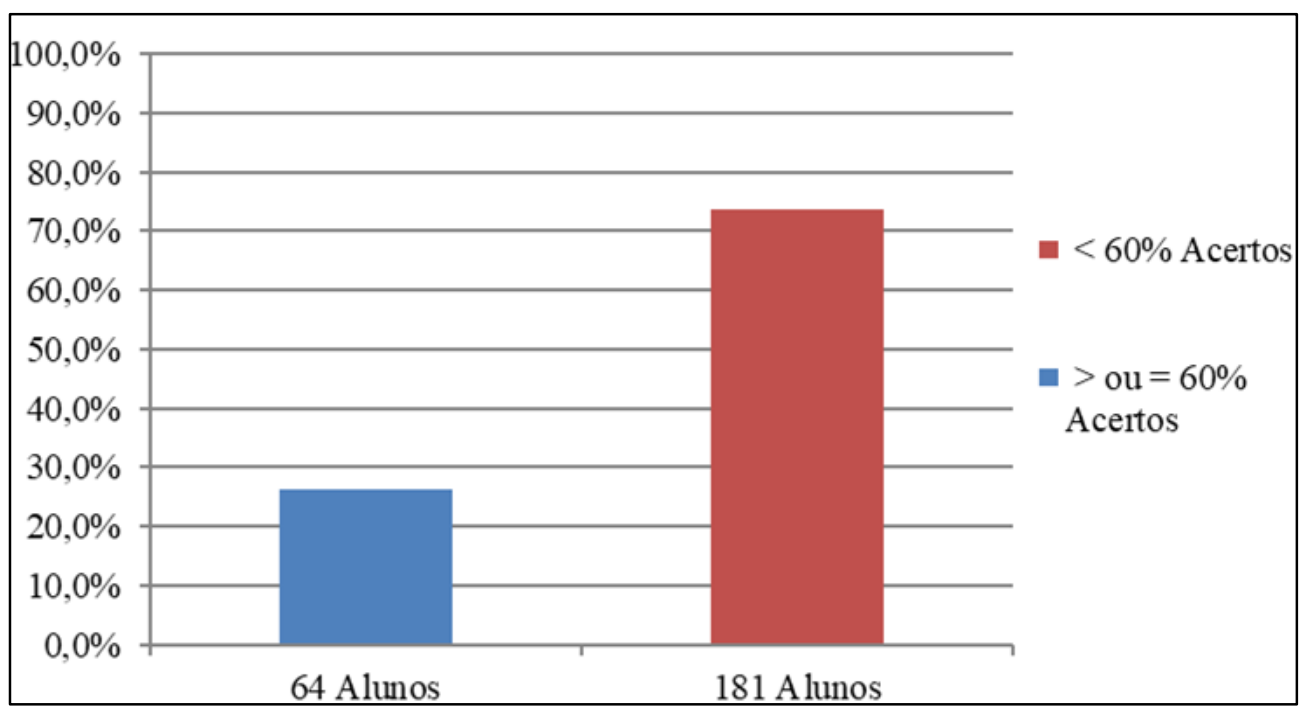

Figura 1 - Resultado oriundo da aplicação dos itens

Fonte: Autores (2018). 
Verifica-se que 73,88\% da amostra, um total de 181 estudantes, não alcançaram o resultado considerado mínimo de $60 \%$ de acertos. Apenas 64 estudantes, ou 26,12\% dos participantes, alcançaram esse objetivo.

O mínimo de acertos considerado razoável neste levantamento foi de $60 \%$ por ser também o mínimo exigido para que um estudante seja considerado aprovado na maioria das escolas brasileiras. Os resultados apresentados na Figura 1 mostram que os estudantes, de maneira geral, apresentam dificuldades de lidar com noções básicas que remetem ao mundo financeiro, apesar de conferirem importância desse tema para suas vidas. Tal dado promove reflexões sobre a importância de buscar o fortalecimento das discussões da Educação Financeira no âmbito da escola (SILVA; CAMPOS, 2014).

\subsection{Importância da Aprendizagem de Temáticas de Matemática Financeira}

Os conhecimentos para lidar com a vida financeira podem subsidiar a construção da cidadania. Assim, buscou-se inicialmente explicitar o quanto os estudantes do $3^{\circ}$ Ano do Ensino Médio consideram a aprendizagem dos temas de Matemática Financeira importante para suas vidas.

Reflexão Crítica 1: O quanto você considera importante a aprendizagem de temas de Matemática Financeira para sua vida?

a) Não tem importância nenhuma estudar os temas de Matemática Financeira.

b) Pouco importante estudar os temas de Matemática Financeira.

c) Razoavelmente importante estudar os temas de Matemática Financeira.

d) Muito importante estudar os temas de Matemática Financeira.

Quadro 10 - Item envolvendo a importância da aprendizagem de temas de Matemática Financeira Fonte: Autores (2018).

Após o tratamento dos dados, chegou-se na Figura 2 que ilustra o cenário:

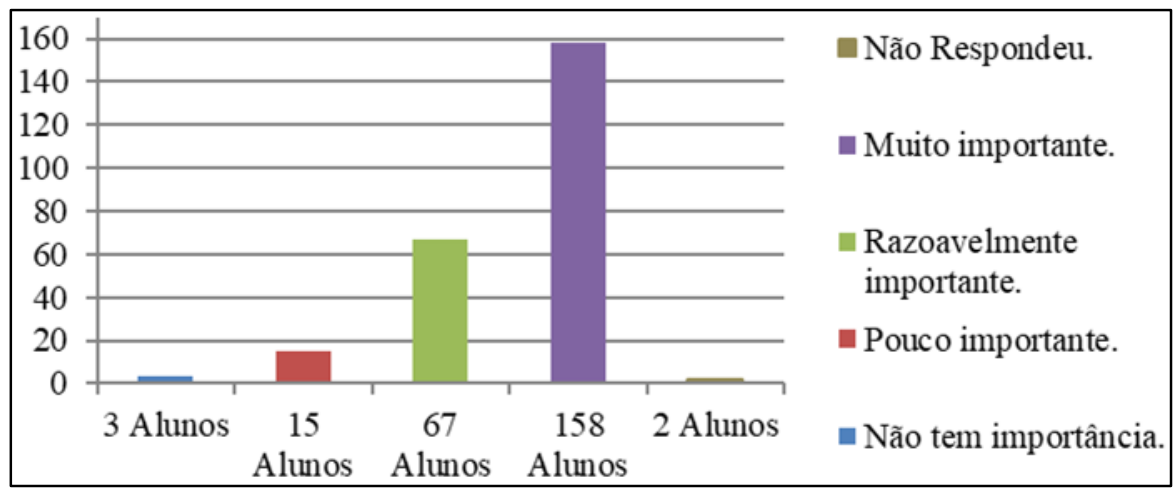

Figura 2 - Reflexão Crítica 1 - O quanto você considera importante a aprendizagem de temas de Matemática Financeira para sua vida?

Fonte: Autores (2018). 
ALMEIDA, W. R. de et al. Levantamento do desempenho em matemática financeira de estudantes concluintes do 16 ensino médio da cidade de Guanhães

De acordo com a Figura 2, considerando apenas os estudantes que responderam à pesquisa, a maioria (um total de 158 estudantes ou 65,02\% dos participantes) considerou a aprendizagem dos temas de Matemática Financeira como algo muito importante para sua vida. Se considerarmos somados a estes, aqueles que consideram o conteúdo razoavelmente importante totalizam-se 225 estudantes ou 92,59\% da amostra que atribuem algum grau de relevância ao tema. Na perspectiva oposta, apenas 3 estudantes que a consideraram sem importância e 15 com pouca importância.

Este cenário demonstra que, para a quase totalidade dos discentes do $3^{\circ}$ Ano das Escolas Estaduais do município de Guanhães, a aprendizagem dos temas de Matemática Financeira é importante para sua vida cotidiana. Este dado corrobora para que as escolas busquem refletir sobre a abordagem da Matemática Financeira atual, reformulando seus currículos, tendo a BNCC (BRASIL, 2018) como subsídio para avançar para abordagens de Educação Financeira.

A seguir, apresenta-se o resultado do último item, o qual tem o objetivo de explicitar o panorama relacionado à apropriação de temas de Matemática Financeira ao longo da Educação Básica.

Reflexão Crítica 2: Você considera que os temas de Matemática Financeira ofertados durante a Educação Básica deram base suficiente para resolver as questões propostas?

a) os temas de Matemática Financeira ofertados não forneceram nenhuma base para a análise das questões.

b) os temas de Matemática Financeira ofertados foram base para análise de menos de 4 questões.

c) os temas de Matemática Financeira ofertados foram base para análise de 4 a 6 questões.

d) os temas de Matemática Financeira ofertados foram base para análise de todas as questões.

Quadro 11 - Item envolvendo as contribuições dos temas de Matemática Financeira para a resolução das situações propostas

Fonte: Autores (2018).

Na Figura 3 representa a compilação dos resultados obtidos após aplicação dos itens supracitados:

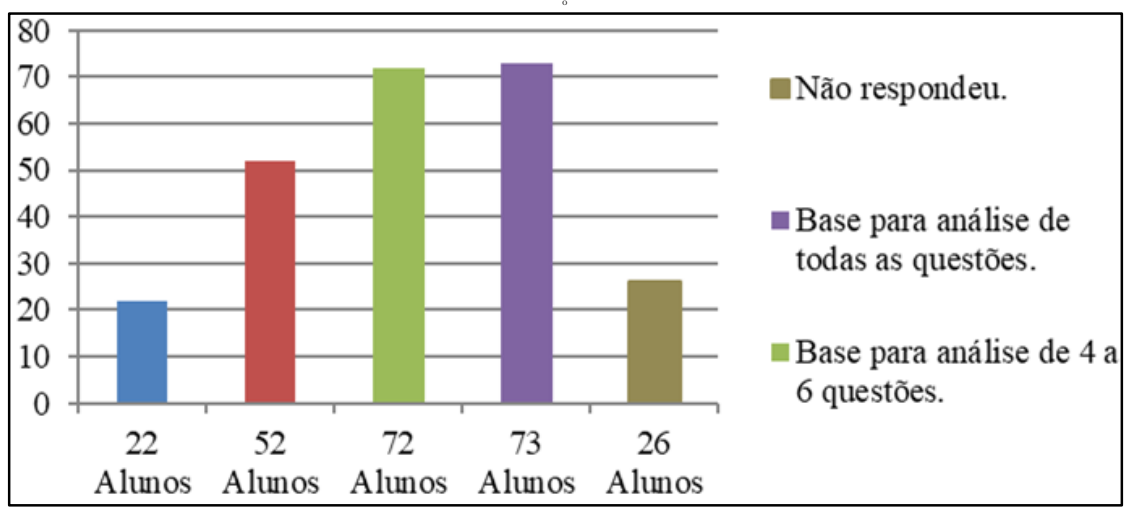

Figura 3 - Reflexão Crítica 2 - Você considera que os temas de Matemática Financeira ofertados durante a Educação Básica deram base suficiente para resolver as questões propostas?

Fonte: Autores (2018). 
A análise da Figura 3 permite verificar que dos 245 participantes da pesquisa, 26 não responderam à essa pergunta. Daqueles que responderam, 73 estudantes ou 33,33\% dos respondentes consideraram que os temas de Matemática Financeira ofertados durante a Educação Básica deram base suficiente para resolver todas as questões do questionário. Já 72 estudantes afirmaram que os conteúdos ofertados deram base para análise de 4 a 6 questões, ou seja, $32,88 \%$.

$\mathrm{Na}$ outra frente, 52 discentes ou $23,75 \%$ afirmaram que os temas vivenciados deram base suficiente para resolver menos de 4 questões, e ainda 22 estudantes ou 10,04\% afirmaram que os temas ofertados durante toda a Educação Básica não forneceram nenhuma base para analisar as questões propostas no questionário.

Os dados em questão provocam reflexões sobre a importância de uma formação Matemática que presuma a apropriação e a transposição dos conteúdos dessa disciplina para a vida cidadã (COUTINHO; TEIXEIRA, 2015). Nesse sentido, a valorização de abordagens de práticas financeiras da sociedade deve ter lugar de destaque nos currículos. Em outras palavras, “... o ensino e uso dos modelos matemático/financeiro em sala de aula devem estar em consonância com as necessidades, os interesses e as experiências de vida dos estudantes" (ROSETTI JUNIOR; SCHIMIGUEL, 2009, p. 2).

\section{CONSIDERAÇÕES FINAIS}

As situações que demandam conhecimento para lidar com aspectos financeiros estão presentes no dia a dia das pessoas. Porém, muitas delas não são devidamente refletidas com os estudantes, pois as listas de conteúdos dos livros didáticos acabam por tomar espaço excessivo do currículo. Dessa forma, ao fim da etapa da Educação Básica, não é incomum que egressos não saibam decidir racionalmente sobre as relações comerciais do seu dia a dia.

O presente trabalho, como recorte de um estudo maior, buscou apresentar um levantamento sobre o desempenho dos estudantes do $3^{\circ}$ ano da rede estadual do município de Guanhães quando submetidos a situações problema de Matemática Financeira, bem como estes percebem essa temática.

Os resultados mostram a necessidade de ações que impulsionem a aprendizagem dos estudantes no sentido de que adquiram habilidades e competências para solucionar problemas básicos que demandem um repertório de conhecimento financeiro. 
ALMEIDA, W. R. de et al. Levantamento do desempenho em matemática financeira de estudantes concluintes do

É importante destacar que os estudantes demonstram consciência ao apontar a importância de estudar e compreender temas da Matemática Financeira. Ao afirmarem que, tais temas se fazem presentes no currículo, os estudantes corroboram para que a escola e os educadores reflitam sobre a forma de abordagem destes conteúdos, pois o índice de acertos no questionário foi realmente preocupante. Uma contradição observada está relacionada com o fato de que a maioria dos estudantes reconhece a importância de se estudar temas de Matemática Financeira, porém o resultado dos questionários aplicados demonstra que estes, em sua maioria, não conseguiram realizar corretamente um mínimo estabelecido de 60\% (sessenta por cento) das questões propostas.

É necessário dar maior importância aos temas relacionados ao mundo financeiro durante todo o percurso da Educação Básica, oportunizando aos estudantes o conhecimento de conceitos desse conteúdo para as relações de trabalho e consumo, e orientando-os no planejamento financeiro pessoal e familiar. Tal perspectiva exige uma metodologia pautada no ensino para a cidadania, não mais admitindo somente processos de memorização de fórmulas sem a devida interpretação de suas aplicações nas situações-problema que refletem aspectos de tomadas de decisão de um cidadão ativo. Espera-se, com essas reflexões, que os educadores se sintam instigados a inovar suas práticas, construir, reconstruir e aprimorar suas próprias metodologias e experiências.

Precisamos recorrer a Bauman (2010), o qual faz a seguinte ponderação:

[...] a atual "contração do crédito" não é resultado do insucesso dos bancos. Ao contrário, é o fruto, plenamente previsível, embora não previsto, de seu extraordinário sucesso. Sucesso ao transformar uma enorme maioria de homens, mulheres, velhos e jovens numa raça de devedores. Alcançaram seu objetivo: uma raça de devedores eternos e a autoperpetuação do "estar endividado", à medida que fazer mais dívidas é visto como o único instrumento verdadeiro de salvação das dívidas já contraídas. O hábito universal de buscar mais empréstimos era visto como a única forma realista (ainda que temporária) de suspensão da execução da dívida (BAUMAN, 2010, p. 31).

A escola necessita refletir e avançar para o desenvolvimento de práticas de Educação Financeira, pois os jovens, em especial, os participantes desta pesquisa, serão os futuros trabalhadores e, consequentemente, terão repercussões importantes para a economia do país. Desta forma, temos que compreender a indissociabilidade na relação Educação↔Trabalho (ANTUNES, 1999; SAVIANI, 1989, 2007).

Conforme já citado, esta investigação é parte de um estudo maior que se iniciou com a fase diagnóstica. O levantamento realizado na citada fase foi importante para apontar evidências do conhecimento relacionado à temática financeira para subsidiar etapas futuras. Tais 
evidências, embora oriundas da análise dos dados obtidos por um questionário onde os participantes tiveram que apontar uma resposta, são importantes e suscitam reflexões robustas para futuras fases da pesquisa, pois os itens avaliados foram advindos de avaliações oficiais que se estruturam por uma lógica que leva em consideração o currículo da Educação Básica, ou seja, situações-problema que deveriam estar ao alcance dos formandos dessa etapa.

Sendo assim, futuras fases do estudo buscarão discutira importância da Educação Financeira com professores e estudantes das escolas da região. Que esses novos estudos possam envolver e impactar a sala de aula refletindo sobre as mudanças na sociedade do consumo, visando contribuir com os objetivos de desenvolvimento sustentável da Agenda 2030, em especial o objetivo relacionado à Educação, que visa garantir a alfabetização e o conhecimento básico de Matemática a todos os jovens e à uma proporção significativa de homens e mulheres (ONU, 2015).

\section{REFERÊNCIAS}

A ESTRADA REAL. Disponível em: http://www.institutoestradareal.com.br/estradareal. Acesso em: 09 nov. 2019.

ANTUNES, R. Os sentidos do trabalho: ensaio sobre a qualificação e a negação do trabalho. São Paulo: Boitempo, 1999.

BAUMAN, Z. Vida para consumo: a transformação das pessoas em mercadorias. Rio de Janeiro: Jorge Zahar, 2008.

BAUMAN, Z. Capitalismo parasitário e outros temas contemporâneos. Rio de Janeiro: Zahar Editores, 2010.

BORGES, L. Salve seu bolso: o mais completo guia para antes, durante e depois da compra. São Paulo: Petrópolis, 1999.

BRASIL. Lei no 9394, de 20 de dezembro de 1996: Diretrizes e Bases da Educação Nacional, promulgada em 20 de dezembro de 1996.

BRASIL. Parâmetros Curriculares Nacionais. Brasília: MEC/SEF, 1999.

BRASIL. Parâmetros Curriculares Nacionais, Ensino Médio. Brasília: MEC/Secretaria de Educação Básica, 2002.

BRASIL. Base Nacional Comum Curricular: Ensino Médio. Brasília: MEC/Secretaria de Educação Básica, 2018. 
COUTINHO, C. de Q. S.; TEIXEIRA, J. Letramento financeiro: um diagnóstico de saberes docentes. Revista Eletrônica de Educação Matemática, Caxias do Sul, v. 10, n. 2, p. 1-22, 2015.

DAL-FARRA, R. A.; LOPES, P. T. C. Métodos mistos de pesquisa em educação: pressupostos teóricos. Nuances: estudos sobre Educação, Presidente Prudente, v. 24, n. 3, p. 67-80, set./dez. 2013.

D’AMBROSIO, U. A matemática nas escolas. Educação Matemática em Revista, Rio Grande, v. 9, n. 11, abr. 2002.

DANTAS, G. C. da S. Consumismo: mundo educação. 2007. Disponível em: https: //mundoeducacao.bol.uol.com.br/psicologia/consumismo.htm. Acesso em: 24 jun. 2018.

GIL, A. C. Como elaborar projetos de pesquisa. São Paulo: Atlas, 2002.

INSTITUTO BRASILEIRO DE GEOGRAFIA E ESTATÍSTICA. Panorama do município de Guanhães - MG. Disponível em:

https://cidades.ibge.gov.br/brasil/mg/guanhaes/panorama. Acesso em: 07 ago. 2019.

INEP - INSTITUTO EDUCACIONAL DE ESTUDOS E PESQUISAS EDUCACIONAIS ANÍSIO TEIXEIRA. Enem - Provas e Gabaritos. Disponível em: http://portal.inep.gov.br/web/guest/provas-e-gabaritos. Acesso em: 07 ago. 2019.

INEP - INSTITUTO EDUCACIONAL DE ESTUDOS E PESQUISAS EDUCACIONAIS ANÍSIO TEIXEIRA. Encceja - Provas e Gabaritos. Disponível em:

http://portal.inep.gov.br/educacao-basica/encceja/provas-e-gabaritos. Acesso em: 07 ago. 2019.

LAKATOS, E. M.; MARCONI, M. de A. Fundamentos de metodologia científica. 5. ed. São Paulo: Atlas, 2003.

LIMA, I. G; SAUER, L. Z. Razão e emoção em ambientes de aprendizagem: em busca da unidade. In: VALENTINNI, C. B.; SOARES, E. M. S. (Orgs.). Aprendizagem em ambientes virtuais: compartilhando ideias e construindo cenários. Caxias do Sul, RS: Educs, 2005.

LOPES, K. T. Uma investigação sobre o ensino de porcentagem no $6^{\circ}$ ano do Ensino Fundamental. 2013. 164 p. Dissertação (Mestrado Profissional em Educação Matemática) Universidade Federal de Juiz de Fora, Juiz de Fora, 2013.

MINAS GERAIS. Conteúdo Básico Comum (CBC) de Matemática do Ensino Médio. Disponível em: http://twixar.me/js1T. Acesso em: 04 abr. 2007.

NAÇÕES UNIDAS NO BRASIL - ONU BR. A Agenda 2030. Disponível em: https://nacoesunidas.org/pos2015/agenda2030/. Acesso em: 11 nov. 2019 
POTRICH, A. C. G.; VIEIRA, K. M. Afinal, a alfabetização financeira apresenta uma mudança linear entre grupos distintos de perfil? In: CONGRESSO BRASILEIRO DE ECONOMIA E FINANÇAS COMPORTAMENTAIS, 5., 2018, São Paulo.

REIS, S. R. Matemática financeira na perspectiva da educação matemática crítica. 2013. 113 p. Dissertação (Mestrado Profissional em Matemática em Rede Nacional) - Universidade Federal de Santa Maria, Santa Maria, 2013.

ROSETTI JUNIOR, H.; SCHIMIGUEL, J. Educação matemática financeira: conhecimentos financeiros para a cidadania e inclusão. Revista Científica Internacional: Inter Science Place, Campus dos Goytacazes, v. 2, n. 9, p. 1-13, out./nov. 2009.

SAITO, A. T. Uma contribuição ao desenvolvimento da educação em finanças pessoais no Brasil. 2007, 152 p. Dissertação (Mestrado em Administração) - Universidade de São Paulo, São Paulo, 2007.

SAVIANI, D. Sobre a concepção de politecnia. Rio de Janeiro: Fiocruz, 1989.

SAVIANI, D. Trabalho e educação: fundamentos ontológicos e históricos. Revista Brasileira de Educação, Rio de Janeiro, v. 12, n. 34, p. 152-180, jan./abr. 2007.

SILVA, A. M.; CAMPOS, M. B. A Produção de significados de estudantes do ensino fundamental para tarefas de educação financeira. In: Perspectivas da Educação Matemática, Campo Grande, v. 7, 2014.

SILVA, A. M.; POWELL, A. B. Um programa de educação financeira para a matemática escolar da educação básica. In: ENCONTRO NACIONAL DE EDUCAÇÃO MATEMÁTICA, 11., 2013, Curitiba. Anais [...]. Curitiba, 2013.

SILVA, A. M.; POWELL, A. B. Educação financeira na escola: a perspectiva da organização para cooperação e desenvolvimento econômico. Boletim Gepem, Seropédica, v. 66, p. 3-19, 2015.

TRILHAS DO RIO DOCE. Disponível em: http://www.trilhasdoriodoce.com.br/. Acesso em: 09 nov. 2019.

\section{DADOS DOS AUTORES}

Nome: Wálmisson Régis de Almeida

E-mail: walmisson.almeida@ifmg.edu.br

Currículo Lattes: http://lattes.cnpq.br/6332544449538505

Mestre em Matemática pela Universidade Federal de São João Del Rei - UFSJ (CAPES/PROFMAT); pós-graduado em Gestão Educacional pelo SENAC - MG; pós-graduado em Matemática pela Universidade Federal de São João Del Rei - UFSJ; graduado em Matemática (Licenciatura Plena) pelo Centro Universitário de Sete Lagoas - UNIFEMM; graduado em Odontologia pela Faculdade Federal de Odontologia de Diamantina - atual Universidade Federal dos Vales do Jequitinhonha e Mucuri - UFVJM. Atualmente é professor efetivo da área de Matemática do Instituto Federal de Minas Gerais - Campus São João 
Evangelista, atuando como Coordenador da Licenciatura em Matemática do IFMG - Campus São João Evangelista desde dezembro de 2017.

Nome: José Fernandes da Silva

E-mail: jose.fernandes@ifmg.edu.br

Curriculum Lattes: http://lattes.cnpq.br/3777760667525907

Pós-Doutor em Educação Matemática pela PUC/SP. Doutor em Educação Matemática pela UNIAN/SP. Graduado em Matemática pela UNIMONTES (2002). Graduado em Pedagogia pela UNICSUL (2017). Especialista em Ensino Superior pela UCAM (2003). Mestre em Educação pela - UNINCOR, (2011). Atualmente é professor efetivo no Instituto Federal de Minas Gerais - Campus São João Evangelista, onde coordenou o Curso de Licenciatura em Matemática de 2010 a 2014.

Nome: Graziele Chaves Pereira

E-mail: grazychaves11@gmail.com.br

Curriculum Lattes: http://lattes.cnpq.br/1781369680290640

Licenciada em Matemática pelo Instituto Federal de Minas Gerais - Campus São João Evangelista. Graduada em Administração de Empresas pela Faculdade do Vale Elvira Dayrell.

Nome: Higor Nilton Braga de Matos

E-mail: higor025@gmail.com

Curriculum Lattes: http://lattes.cnpq.br/8134781424725602

Licenciado em Matemática pelo Instituto Federal de Minas Gerais - Campus São João Evangelista. 